\title{
A critical evaluation of serum lipase and amylase as diagnostic tests for acute pancreatitis
}

\author{
Sarfaraz Jasdanwala* and Mark Babyatsky \\ Department of Medicine, Monmouth Medical Center, Drexel University College of Medicine, Long Branch, New Jersey, USA
}

\begin{abstract}
Laboratory testing of serum amylase and/or lipase levels are central to the diagnosis of acute pancreatitis (AP) as these tests are quick, cheap, reliable and perhaps the only objective criteria available at the bedside at the time of initial presentation. It is important to understand the physiology and biochemistry of these tests in order to get a clear grasp of their diagnostic utility. Lipase is more specific than amylase and stays elevated longer than amylase due to its longer half-life in serum resulting from renal tubular reabsorbtion. There is no advantage of testing both lipase and amylase, as well as no advantage in serially trending them for monitoring the clinical progress of the patient. They have no role in determining the etiology or severity of acute pancreatitis. The American College of Gastroenterology (ACG) guidelines for the diagnosis and management of acute pancreatitis recommend using 3 times the upper limit of normal (ULN) as the cut off for diagnosis. These cut off levels appear to be quite arbitrary. If the clinical suspicion for acute pancreatitis is high, imaging studies should be performed to confirm or rule out the diagnosis of acute pancreatitis even with low elevation or no elevation of these enzymes. This article is a comprehensive review of the existing literature on serum lipase and amylase as diagnostic tools for AP and their cut off levels used for the diagnosis of AP.
\end{abstract}

\section{Introduction}

Acute pancreatitis (AP) is a very common GI disorder. With increasing number of hospital admissions [1] for AP, the financial impact of this disease is huge [2]. In the year 2009, the total discharges with the principal diagnosis of acute pancreatitis in the United States were 274,119 . This marked a $30 \%$ increase from the year 2000 . The median length of stay was 4 days. The median cost per hospital admission was 6096 USD. The total number of in-hospital deaths due to AP was 2631, which is about $1 \%$ of the total admissions [3]. The American College of Gastroenterology (ACG) practice guidelines for the diagnosis and management of AP recommend that the diagnosis of AP be established by the presence of 2 of the following 3 criteria: 1 ) Abdominal pain consistent with AP 2) serum lipase and/or amylase greater than 3 times the upper limit of normal (ULN) 3) characteristic findings from abdominal imaging (Contrast Enhanced CT or MRI) [4].

Pain from AP is most commonly epigastric, but could also be in the left or right upper quadrant. It can radiate to the back, flanks or chest. It is usually constant. The intensity is variable, but is most often severe. This description of the pain is somewhat non-specific. Pain may be absent or may be overshadowed by the early appearance of organ dysfunction. The history of pain may not be available in many patients - as for example in elderly patients or demented patients. The only two objective criteria for diagnosis are elevated serum lipase and/ or amylase values and imaging findings characteristic of AP. Contrast Enhanced CT (CECT) of the abdomen is conventionally considered the gold standard for the diagnosis of AP. It is more than $90 \%$ sensitive and specific for the diagnosis of AP [5]. However, imaging evidence is often not available at the time of diagnosis [6]. If available, in a good number of patients with AP, CT scan can be normal, especially early in the course of the disease. Also, as per the practice guidelines of the ACG, it is not recommended to obtain a CT scan of the abdomen at the time of admission. CECT is recommended when the diagnosis of
AP is in doubt or if the patient fails to improve/worsens clinically after 48 hours of admission. This is due to the cost involved and the lack of sensitivity of CT early in the course of the disease. Hence, the only objective diagnostic criteria routinely available at the time of initial patient contact are serum levels of pancreatic enzymes lipase and/or amylase.

\section{Lipase \\ Biochemistry}

Use of lipase for the diagnosis of AP was first described in the early in 1930s by Cherry and Crandall [7]. Serum lipase is derived mainly from pancreatic acinar cells where it is stored in the form of granules. More than $99 \%$ of the stored lipase gets excreted from the apical poles of the acinar cells into the ductal system of the pancreas. Under physiological conditions less than $1 \%$ diffuses from the basilar pole of the acinar cells to lymphatics and capillaries, and from there gaining access to the general circulation. Lipase starts to increase within $4-8 \mathrm{~h}$ after the onset of acute pancreatitis, peaks at $24 \mathrm{~h}$, and starts to decrease within 8-14 days [8] (Table 1). Half-life of lipase is 6.7 to 13.7 hours in plasma [9]. It is longer than the half-life of amylase and as a result its activity remains increased longer than that of amylase. Lipase is filtered by the glomerulus and thereafter, reabsorbed by the tubules. This reabsorption may be responsible for the longer half-life of lipase as compared to amylase, which does not undergo tubular reabsorption.

Correspondence to: Sarfaraz Jasdanwala, Department of Medicine, Monmouth Medical Center, Drexel University College of Medicine, 300 Second Aveneu, Long Branch, New Jersey, USA, Tel: 732-923-5000; Ext 1450; E-mail: s.a.jasdanwala@gmail.com

Key words: acute pancreatitis, lipase, amylase, enzymes, diagnosis of pancreatitis

Received: April 18, 2015; Accepted: May 08, 2015; Published: May 12, 2015 
Table 1: Kinetics of lipase and amylase elevations in acute pancreatitis.

\begin{tabular}{|l|l|l|l|}
\hline Test & Rise & Peak & Return to baseline \\
\hline Lipase & 4-6 hours & 48 & $8-14$ days \\
\hline Amylase & 2-4 hours & $24-48$ & $5-7$ days \\
\hline
\end{tabular}

Table 2: Conditions associated with elevated serum lipase levels.

\begin{tabular}{|l|}
\hline Acute cholecystitis \\
\hline Post cholecystecomy syndrome \\
\hline Extrahepatic biliary obstruction \\
\hline Bowel obstruction or infarction \\
\hline Duodenal ulceration \\
\hline Pancreatic calculus \\
\hline Pancreatic carcinoma \\
\hline Diabetic ketoacidosis \\
\hline Post-ERCP/trauma \\
\hline Fat embolism \\
\hline Crush injury \\
\hline Bone fracture \\
\hline Heparin infusion \\
\hline Idiopathic elevation \\
\hline Inflammatory Bowel Disease \\
\hline Familial pancreatic hyperenzymemia \\
\hline Macrolipasemia \\
\hline
\end{tabular}

Lipase also undergoes metabolism by the renal tubules.

\section{Sensitivity and specificity}

The reported sensitivity of lipase varies in different studies. The range for its sensitivity is $85 \%$ to $100 \%$ [10]. It is not clear whether it is more sensitive as compared to serum amylase. Some studies show that it is more sensitive as compared to amylase, but others show it to be less $[9,11]$. Lipase elevation is not specific for AP. There is a host of conditions besides AP where it is elevated (Table 2) [12]. Despite this, overall it may be slightly superior to amylase in terms of specificity. However, it is now recognized that lipase can be elevated in as many conditions other than AP as amylase [13]. Overall, to determine whether lipase is superior to amylase is a very challenging task and no study conclusively answer this question. There are several reasons why it is challenging:

There is no convenient third test that can be used as a reference gold standard for comparing the two head to head. CT scan, which is the imaging gold standard and has been used as reference to estimate the sensitivity of lipase and amylase, has several limitations including lack of sensitivity early in the course of the disease and lack of easy availability.

Accuracy of any test, also known as diagnostic efficiency or predictive value, is dependent on the prevalence of the disease [14]. Studies that compare the accuracy of lipase and amylase have been performed in settings with widely different prevalence of the disease [10,15-18]. Hence, it is difficult to compare these studies with each other. Further, for both lipase and amylase the ULN is determined from a population of young healthy subjects $[12,19]$. Thus, levels above the ULN do not necessarily mean presence of AP.

Some studies make diagnostic discrimination based on peak values chosen from serial measurements rather than initial single level at the time of presentation [20]. This is in contrast to the real life situation where the diagnosis has to be made based on a single level at the time of presentation.
Despite these limitations it is possible to conclude that the potential advantages of lipase over amylase include slightly better specificity, longer half-life and hence greater sensitivity in patients who present late and greater sensitivity for alcoholic pancreatitis. This is discussed in detail in subsequent sections.

\section{Amylase \\ Biochemistry}

Amylase has been in use clinically long before lipase was available. In 1919 it was used first time as a laboratory test for diseases of the pancreas [21]. Levels of amylase often start to increase by 6 to 24 hours after the onset of AP, usually peak at 48 hours and typically over the period of next 5 to 7 days, tend to normalize [21,22] (Table 2). Hence, it has a shorter half-life as compared to lipase. As a consequence, the amylase levels tend to return to normal even when the inflammation in the pancreas has not subsided. The molecular weight of amylase is 50,000 Daltons. It has a low molecular weight and as a result can easily pass through the glomerulus into the urine. It has a relatively short half-life of 2 hours and is excreted by the kidney. In the past it was shown that urinary amylase had good sensitivity for diagnosing AP [23]. However in comparison to serum amylase and other serum tests, urinary amylase was found not to have superior diagnostic ability [24]. The only advantage of urinary amylase was the rapid availability of the results at bedside. However serum amylase is also very quick and has better diagnostic accuracy overall. Also, the specificity of urinary amylase is very poor [25]. Hence, estimation of urine amylase has been discarded from routine clinical practice. The levels of amylase also tend to increase with age. Amylase levels are low in infancy and rise slowly and reach to adult levels by the age of 10. Upper limit of normal increases by about $40 \%$ after the eight decade of life [12].

\section{Sensitivity and specificity}

Using CT abdomen or Ultrasound abdomen as the gold standard to determine the diagnosis of AP, the sensitivity of serum amylase is $81-95 \%$ in various studies [26]. It has been shown that in about $19 \%$ of patients with CECT confirmed diagnosis of AP, amylase levels maybe completely normal [27]. There are several reasons for the low sensitivity of amylase. Amylase levels are often not as elevated to the same extent in alcoholic pancreatitis as in pancreatitis of other etiology [28]. In as study of 68 episodes of acute alcoholic pancreatitis over a one-year period, the serum amylase level was normal at the time of hospitalization in $32 \%$ of the cases [29]. In hypertriglyceridemic AP, hyperlipidemia tends to interfere with serum amylase level measurement and results in a falsely low level [30] by a mechanism, which is not completely understood. However, when serum of patients with elevated lipids and falsely normal amylase levels is diluted, amylase gets elevated. This proves that there is an inhibitor, not yet characterized, in the circulation, which is interfering with the assessment of amylase levels. Another major deterrent to sensitivity is the short half-life. Amylase levels tend to peak at 48 hours after the onset of pain after which the sensitivity declines very rapidly [27,31].

Amylase has poor specificity [13]. Depending upon the technique used for measuring serum amylase and the multiple of ULN used as cut off, the specificity varies anywhere in the range of $71 \%$ to $99 \%$ [32]. This is perhaps the greatest limitation of serum amylase as a diagnostic test for AP. The wide ranges of abdominal and extra abdominal conditions besides AP, which result in elevated serum amylase levels, are summarized in the table 3 . 
Table 3: Conditions associated with elevated serum amylase levels.

\begin{tabular}{|l|} 
Abdominal disorders \\
Pancreatic disorders: chronic pancreatitis, pseudocysts, pancreatic trauma, pancreatic cancer, post ERCP \\
Non-pancreatic intra-abdominal conditions: perforated bowel, mesenteric infarction, intestinal obstruction, appendicitis, peritonitis, abdominal aortic aneurysm, ruptured ectopic \\
pregnancy, fallopian and ovarian cysts, salpingitis, hepatitis \\
Extra-abdominal conditions \\
Salivary diseases, renal failure, keto-acidosis, pneumonia, cerebral trauma, burns, anorexia nervosa, bulimia, non abdominal surgery \\
Macroamylasemia \\
Idiopathic hyperamylasemia \\
Familial and non familial \\
Drug induced \\
Definite association: \\
azathioprine, L-asparginase, sulfonamides, tetracycline, didanosine, methyldopa, estrogens, furosemide, pentamidine, 5-aminosalicylic acid compounds, valproic acid, salicylate, thiazide, \\
calcium, vinca alkaloids \\
Probable association: \\
glucocorticoids, nitrofurantoin, phenformin, rifampin, FK-506 (tacrolimus), metronidazole, 6-mercaptopurine, procainamide, diphenoxylate, chlorthalidone, cimetidine, cytosine \\
arabinoside, cisplatin, cyclosporin A
\end{tabular}

\section{Macrolipasemia and macroamylasemia}

Macro amylases are large molecules, which are about 3 to 5 times the size of normal amylase molecule [33]. Macro amylases are seen in $0.1 \%$ of the general population but their prevalence can be as high as $2.7 \%$ of the hospitalized patients [34]. It is very important to recognize the existence of this entity because patients who have otherwise unexplained hyperamylasemia may be subjected a variety of unnecessary diagnostic or therapeutic procedures.

In rare cases, lipase can form a complex with immunoglobulin A resulting in persistently elevated lipase levels in the absence of any clinical features of AP. This entity is called macrolipasemia, and although less frequently described as compared to macroamylasemia, remains important for similar reasons in patients with other wise unexplained lipase elevation [35]

\section{Cinical chemistry aspects of lipase and amylase estimations}

Several methods are available for lipase and amylase estimation. Estimation time and cost are highly variable depending upon the principle method, the type of reagent and the instrument used for the reaction as well as the lipase and amylase levels in the sample. Using the spectro-photometric technique, the average time for running an assay is 5-10 minutes for most of the samples and the average cost per assay to the provider is approximately USD 2.50 and the median Medicare reimbursement is approximately USD 100 . The time and cost for both lipase and amylase assays is identical. If the levels of lipase or amylase are very high, it may take approximately another 10-15 minutes to run the assay depending upon the number of dilutions required (Personal communication, Monmouth Medical Center Biochemistry laboratory January 2014). There are several other useful methods for lipase/ amylase estimation reported in literature. Turbidimetric method has been used in several studies and has been found to be practically useful [8]. However, homogenous immunochemical assays are believed to be the most rapid, easy to perform, free from emulsion problems and accurate in measuring very high or low lipase levels [36].

Any acceptable method for amylase estimation should meet the following criteria [36]: a) There should be defined substrate and reaction product for the method, b) The method should be have zero order kinetics and a continuous monitoring technique with no lag phase or a very short lag phase, c) Endogenous glucose levels must not interfere with the method, d) The method should have sufficient analytical sensitivity to allow accurate measurements within the reference interval.

\section{Role of lipase and amylase in the diagnosis of AP}

The current ACG practice guidelines for the diagnosis and management of AP recommend that in patient presenting with abdominal pain consistent with AP, a serum lipase and/or amylase level greater than 3 times ULN is diagnostic of AP [4].

Lipase and amylase levels have no role in determining the severity or prognosis of AP as evident from previous studies [37-39]. Interestingly, a recent study in pediatric patients validated very high serum lipase levels as a marker of severity. Lipase levels greater than 7 times the ULN within 24 hours of presentation were found to be associated with severe AP and levels below this threshold were found to have a strong correlation to a milder course of AP [40]. The sample size in the study was relatively small as AP, although rising in incidence, is an uncommon disease in children. This finding needs to be revalidated by further studies with a bigger sample size. The reason for extent of lipase elevation to be prognostic in children but not in adults remains enigmatic. The most common etiology for AP in children is GS or idiopathic where as its alcohol followed by GS in adults. This finding could be due to the difference in the underlying pathogenesis of AP in children as compared to adults, and if so, it might be a useful tool to understand it.

Lipase and amylase levels have no role in determining the etiology of AP. Serum lipase: amylase ratio to determine the etiology of AP has been studied by Tenner et al. They found that greater the lipase: amylase ratio, the greater is the specificity of alcohol as the etiology of AP. Also it was noted in the study that only patients with AP secondary to alcohol had lipase: amylase ratios $>5.0$ [41]. However, a further prospective study failed to confirm this finding [42].

Hyperamylasemia occurring in the setting of ERCP provides an interesting insight into the mechanism of amylase elevation. In most of the patients undergoing ERCP, immediately following the procedure, amylase levels are markedly elevated. The levels return to normal within 3-6 hours and the patient is usually asymptomatic with no evidence of pancreatic inflammation. In some patients, the abdominal pain persists along with other signs and symptoms like ileus, low-grade fever or leukocytosis. In these patients the amylase elevation persists for several days. This phenomenon occurs because a sudden in pressure within the pancreatic duct due to dye ingestion results in regurgitation of large 
quantities of pancreatic enzyme into systemic circulation, without any significant pancreatic inflammation. This illustrates a very important fact that hyperamylasemia indicates excessive regurgitation of amylase from the pancreatic secretions into the systemic circulation, and not necessarily pancreatic inflammation. This is perhaps why the absolute amylase levels are higher in gallstone pancreatitis as compared to AP from other etiologies. And this perhaps why the absolute amylase levels provide no prognostic information in patients with AP.

There is no role of following the serial trend of lipase or amylase on a daily basis in patients with acute pancreatitis once the diagnosis has been established [43]. It is not useful for monitoring clinical improvement in the short term. The resolution of pain, overall improvement in clinical status and other markers for severity like C-reactive protein levels at 48 hours from presentation is better for monitoring the clinical progress of AP. If the initial presentation is within 4-5 hours of the onset of abdominal pain and if the levels of either lipase or amylase are normal, it may be worthwhile to repeat the levels in the next couple of hours if the clinical suspicion for AP is high. This is probably the only clinical situation where repeat testing of lipase or amylase in patients presenting with AP can be helpful. If the patient continues to have pain or symptoms weeks after the presentation, checking a repeat lipase level maybe be useful as an elevated lipase can signify persistent pancreatic inflammation, pancreatic ductal obstruction or pseudocyst [44]. In our experience, this recommendation is vague due to several reasons. Firstly, the extent of lipase elevation that can be considered significant in these situations has not been stated and may require further studies. Secondly, to diagnose these late complications imaging modality like MRI or CT is more sensitive and specific compared to serum lipase levels. In the rare event of imaging findings being negative with an elevated lipase level, an elevated lipase level can be an argument for pursuing further workup in the form of Endoscopic Ultrasound or ERCP.

Serum lipase elevation has a better diagnostic value as compared to serum amylase due to its superior specificity. Previously, serum amylase assays had the advantage of being cheap and readily available as compared to lipase, which was very cumbersome and expensive to measure [15]. However, currently lipase assays are widely available and are as cheap, rapid, easy and reliable as amylase assays are. In patients with AP secondary to gallstones the serum amylase tends to be higher at initial presentation as compared to serum levels in AP from other etiologies [45]. However, serum levels of neither amylase nor lipase give any indication regarding the etiology of AP. Thus, there appears to be no advantage of serum amylase as compared to serum lipase as an initial diagnostic test for acute pancreatitis. Potential advantages of serum lipase over serum amylase include a) slightly better specificity b) longer half life and hence greater sensitivity in patients who present late c) greater sensitivity for alcoholic pancreatitis.

Our recommendation would be to use serum lipase first in a patient who presents with abdominal pain consistent with AP. If negative in the presence of high index of clinical suspicion, it may be worthwhile to check serum amylase before proceeding for imaging studies like CT scan of the abdomen or MRI/MRCP or Ultrasound.

\section{Using lipase and amylase in combination}

Prior studies have clearly shown that using lipase and amylase in combination does not improve their diagnostic accuracy [19]. In a very elegant retrospective study by Corsetti et al. [46] the performance of lipase and amylase alone and in combination was studied in patients for whom both these tests were ordered. This study confirmed that simply using both tests together has no advantage over using lipase alone. It was, however, found in the study using logistic regression analysis that use of a statistical model based on logistic regression discriminant function lead to a statistically significant improvement in performance of both tests together over the use of lipase alone. In order to apply this approach clinically, a discriminant rule and analytic techniques, which are specific to the population under study, need to be developed which is not always practically feasible. Thus only if a bivariate approach is used, the combination offers meaningful advantage over use of lipase alone. However, due to the difficulties associated with implementing this approach mentioned above, the use of bivariate approach is not routinely possible. Also, as mentioned before, lipase starts to increase within 4-8 hours of onset of acute pancreatitis and peaks at 24 hours. Amylase on the other hand, starts to rise after 6- 24 hours and peaks at 48 hours. Lipase stays elevated for 8-14 days, much longer than amylase, which stays elevated for 5-7 days [8,21-22]. Therefore, it is clear that from the point of view of diagnosing AP in patients who present very late in the course of the disease, lipase is clearly superior to amylase. Although amylase tends to increase slightly earlier than lipase and peaks slightly earlier too, the difference appears to be not significant enough to affect sensitivity early in the course of the disease.

Thus, routine measurement of both lipase and amylase simultaneously for the diagnosis of acute pancreatitis is likely to add additional cost without any meaningful advantage and hence should be avoided. As an example, in a 600-bedded community hospital in New Jersey, the approximate annual cost of all the amylase assays to the provider was roughly 90,000 USD. (Personal communication, Monmouth Medical Center Biochemistry laboratory, January 2014) Using this as a guide, the total annual cost of amylase assays across the United States is likely to be significant.

\section{Optimal cut off levels for lipase and amylase}

Both lipase and amylase have excellent sensitivity. However, their specificities are not as good as their sensitivities. For a test that is used as a screening test, sensitivity is of greater importance than specificity. Obviously it would be ideal to have high sensitivity and specificity at the same time, but frequently one comes at the cost of the other. For a serious disorder like AP, a test with higher sensitivity would be desirable, especially at the point of initial patient contact. Several receiver operator characteristic (ROC) studies have been conducted to determine the best cut-off that will give optimal specificity and sensitivity combination (Table 4).

The current American College of Gastroenterology Practice Guidelines for the diagnosis and management of acute pancreatitis recommend using 3 times the upper limit of normal (ULN) for both lipase and amylase in making the diagnosis of acute pancreatitis [4]. As per the guidelines, the recommendation to use 3 times the ULN as cut off for diagnosis is arbitrary. Looking at table 4 , it is very clear that specificity does not have a consistent correlation to the level of cut off. In other words, using a higher cut off like 3 times ULN does not always result in higher specificity. For serum lipase, a specificity as high as $99 \%$ can be achieved by using just the ULN as cut - off levels as seen in the study by Steinberg et al. [10]. At the same time using 3 times ULN as cut off is not always associated with higher specificity. The specificity can be as low as $85.7 \%$ despite using 3 times ULN as cut off for lipase as evident from the study by Saez et al. [47]. Similar conclusions can be drawn for serum amylase from Table 4 . In fact, the consensus conference held in Japan to determine the appropriate cut off values for lipase and amylase for the diagnosis of acute pancreatitis 
Table 4: Relationship between cut off values and diagnostic ability of serum lipase and amylase for AP.

\begin{tabular}{|c|c|c|c|c|c|c|c|c|}
\hline Author & n (AP) & Diagnostictest & Assay & $\begin{array}{l}\text { x ULN } \\
\text { cut off }\end{array}$ & Sensitivity & Specificity & $\begin{array}{l}\text { Positive Predictive } \\
\text { Value }\end{array}$ & $\begin{array}{l}\text { Negative Predictive } \\
\text { Value }\end{array}$ \\
\hline \multirow[t]{2}{*}{ Steinberg et al. [1] } & \multirow[t]{2}{*}{$163(39)$} & Lipase & Turbidimetric & 1 & 86.5 & 99.0 & 97.0 & 95.1 \\
\hline & & Amylase & Phadebas & 1 & 94.9 & 86.0 & 75.5 & 97.4 \\
\hline \multirow[t]{2}{*}{ Ventrucci et al. [2] } & \multirow[t]{2}{*}{$189(12)$} & Lipase & ELISA & 1 & 91.7 & 84.7 & 42.3 & 98.9 \\
\hline & & Amylase & Phadebas & 1 & 91.7 & 77.8 & 35.5 & 98.6 \\
\hline \multirow[t]{2}{*}{ Thomson et al. [3] } & \multirow[t]{2}{*}{$168(-)$} & Lipase & Turbidimetric & 1 & 100.0 & 96.0 & 85.0 & 100.0 \\
\hline & & Amylase & Phadebas & 1 & 95.6 & 97.6 & 91.7 & 98.8 \\
\hline \multirow[t]{2}{*}{ Jang et al.[4] } & \multirow[t]{2}{*}{$193(17)$} & Lipase & Turbidimetric & 3 & 53.0 & 99.0 & - & - \\
\hline & & Amylase & Turbidimetric & 5.7 & 100.0 & 99.0 & 97.0 & 100.0 \\
\hline Petrov et al. [5] & $178(64)$ & Lipase & Turbidimetric & 3 & 92.0 & 94.0 & 89.0 & 95.0 \\
\hline \multirow[t]{2}{*}{ Saezet et al. [6] } & \multirow[t]{2}{*}{$72(50)$} & Lipase & Turbidimetric & 3 & 84.0 & 85.7 & 93.4 & 72.0 \\
\hline & & Amylase & Turbidimetric & 3 & 77.0 & 95.0 & 89.0 & 87.0 \\
\hline \multirow[t]{2}{*}{ Chen et al. [7] } & \multirow[t]{2}{*}{$165(98)$} & Lipase & Turbidimetric & 3 & 94.0 & 92.9 & 90.0 & 95.8 \\
\hline & & Amylase & Turbidimetric & 3 & 79.1 & 94.9 & 91.4 & 86.9 \\
\hline \multirow[t]{2}{*}{ Wilson et al. [8] } & \multirow[t]{2}{*}{$188(29)$} & Lipase & Turbidimetric & 3 & 100.0 & 99.0 & 97.0 & 100.0 \\
\hline & & Amylase & Turbidimetric & 3 & 63.0 & 99.0 & 95.0 & 93.0 \\
\hline Kylanpaa- Back et al. [9] & $237(29)$ & Lipase & Turbimetric & $\begin{array}{l}1 \\
3\end{array}$ & $\begin{array}{l}79.0 \\
55.0\end{array}$ & $\begin{array}{l}88.0 \\
99.0\end{array}$ & $\begin{array}{l}49.0 \\
84.0\end{array}$ & $\begin{array}{l}97.0 \\
94.0\end{array}$ \\
\hline Pace et al. [10] & $121(21)$ & Amylase & Phadebas & 1 & 100.0 & 71.6 & 15.6 & 100.0 \\
\hline Raty et al. [11] & $51(13)$ & Amylase & Turbidimetric & 2 & 41.0 & 95.0 & - & - \\
\hline
\end{tabular}

failed to reach a clear-cut conclusion in light of this data summarized in Table 4 [32].

In causes of elevated lipase and amylase other than acute pancreatitis, levels are often 3 times the upper limit of normal. For example, in patients with renal failure lipase elevation as high as 3 times ULN are seen $[48,49]$. Similarly amylase can also be markedly elevated in patients with non-pancreatitis abdominal pain [50,51]. It has been recommended in the past that using 2 times the ULN gives the best overall specificity without compromising on sensitivity [12].

One possible explanation for higher cut off levels not improving the specificity could be the fact that the actual levels of lipase and amylase are not proportional to the severity of the disease. If the rise in serum lipase levels was proportional to the severity of the disease, using higher cut off levels like 3 times ULN as compared to 1 or 2 may have led to improved specificity by excluding the causes of elevated enzymes other than AP. It has been clearly shown that in patients who have very severe necrotizing AP, amylase or lipase levels can be low or even normal. On the other hand, patients with less than 3 times ULN elevation of pancreatic enzymes represent a sizeable group. This group of patient, which has been excluded in previous studies, can also include patients who have severe AP. This group can also include patients with alcoholic $\mathrm{AP}$, as it has been shown that the extent of amylase elevation is not as high in patients with alcoholic AP as compared to patients with nonalcoholic AP [52]. However, a point can be made that the diagnosis of AP can be established from clinical and imaging findings in these patients over the course of time. However a high index of suspicion is needed as a falsely low enzyme level may lead to consideration of other etiologies for the abdominal pain. In contrast to what is conventionally believed, in a study by Lang et al. it was found that lowering the cut-off can result in improved specificity [53]. It remains to be proven if this finding can be reproduced in other studies, however it lends support to the hypothesis that specificity is not consistently linked to cut - off values and that the only parameter that can be linked to cut- off values is sensitivity.

This emphasizes the point that has been endorsed in the ACG clinical practice guidelines as well, that if the clinical suspicion of AP is high, lower enzyme levels cannot rule out AP and any level of enzyme elevation cannot be considered insignificant. Lipase and amylase are usually the first tests performed in any patient suspected to have AP. Hence, based on a careful review of the criteria used to establish cut off levels it seems reasonable that any degree of pancreatic enzyme elevation, even if it is at upper limit of normal, should be regarded as not insignificant if it goes against the overall clinical picture. If the clinical findings are consistent with pancreatitis and if the enzyme levels are elevated but not up to 3 times ULN, the next step should be to obtain imaging like CT abdomen or Ultrasound, especially if the patient has had pain for greater than 48 hours, to rule in or rule out AP. Furthermore, studies specifically looking at the impact on sensitivity of using the 3 times ULN cut off, using imaging studies like CT or Ultrasound as gold standard for comparison, are required.

\section{Conclusion}

The following points can be made about serum lipase and amylase as diagnostic tests for AP from the review of current literature. Either one or both could be elevated in patients with AP. The ACG practice guidelines recommend that either lipase and /or amylase elevation greater than 3 times ULN in patients with abdominal pain consistent with AP is diagnostic of AP. Lipase has slightly better specificity than amylase for AP. Also it is elevated earlier than serum amylase and stays elevated longer than amylase in patients with AP.

In patients with hypertriglyceridemic AP, amylase is not significantly elevated. Lipase elevation, previously thought to be very specific for AP, is now increasingly seen with IBD, DKA and a host of other conditions. The extent of elevation in these non-pancreatitis causes of abdominal pain could be as high as 3 times ULN. Neither lipase nor amylase can be used to predict the severity or etiology of AP.

Continuous elevation of lipase or amylase does not necessarily predict the occurrence of complications following an attack of AP. Studies have shown that there is no diagnostic advantage of using lipase and amylase together routinely. In view of the slightly superior specificity of lipase over amylase and the lack of benefit from routinely 
performing both tests together, some Emergency Departments are checking only serum lipase in patients presenting with abdominal pain consistent with AP. This approach seems justifiable based on the current review of literature. Routine use of both together adds to cost and is not recommended.

Conditions under which the diagnosis of AP can be missed by just using lipase or amylase include; Very early in the course of the disease, example - a patient already admitted to the hospital develops abdominal pain since one hour; history of abdominal pain is not available, example - demented patients, critically ill patients and severe necrotizing AP.

There is no definite correlation between cut off values and specificity. Using a higher cut off values does not necessarily result in improved specificity, and similarly using lower cut off values does not necessarily result in diminished specificity. One possible explanation for this could be the fact that the level of elevation of serum lipase or amylase is not related to the severity of the disease. Although the correlation is not absolutely linear from various ROC studies, increasing cut off may lead to diminished sensitivity. Further studies to quantify this decrease in sensitivity by using 3 times ULN as cut off as compared to using 2 times ULN or ULN as cut off are needed. If the clinical suspicion of AP is high, a low degree of enzyme elevation cannot rule out the diagnosis of AP, a recommendation endorsed by the ACG practice guidelines.

\section{References}

1. Fagenholz PJ, Castillo CF, Harris NS, Pelletier AJ, Camargo CA Jr (2007) Increasing United States hospital admissions for acute pancreatitis, 1988-2003. Ann Epidemiol 17: 491-497. [Crossref]

2. Fagenholz PJ, Castillo CF, Harris NS, Pelletier AJ, Camargo CA Jr (2007) Direct medical costs of acute pancreatitis hospitalizations in the United States. Pancreas 35: 302-307. [Crossref]

3. Peery AE, Dellon ES, Lund J, Crockett SD, McGowan CE, et al. (2012) Burden of gastrointestinal diseases in the United States: 2012 update. Gastroenterol 143: 11791187. [Crossref]

4. Tenner S, Baillie J, De Witt John, Vege SS (2013) American College of Gastroenterology Guideline: Management of Acute Pancreatitis. Am J Gastroenterol 108: 1400-1415. [Crossref]

5. Balthazar EJ (2002) Acute pancreatitis: assessment of severity with clinical and CT evaluation. Radiology 223: 603-613. [Crossref]

6. Balthazar EJ (1989) CT diagnosis and staging of acute pancreatitis. Radiol Clin North Am 27: 19-37. [Crossref]

7. Cherry IS, Crandall LA (1932) The specificity of pancreatic lipase: Its appearance in the blood after pancreatic injury. Am J Physiol 100: 266-273.

8. Tietz N, Shuey D (1993) Lipase in serum-the elusive enzyme: an overview. Clin Chem 39: 746-756. [Crossref]

9. Apple F, Benson P, Preese L, Eastep S, Bilodeau L et al (1991) Lipase and pancreatic amylase activities in tissues and in patients with hyperamylasemia. Am J Clin Pathol 96: 610-614. [Crossref]

10. Steinberg WM, Goldstein SS, Davis ND, Shammaa J, Anderson K (1985) Diagnostic assays in acute pancreatitis. Ann Intern Med 102: 576-580. [Crossref]

11. Thomson HJ, Obekpa PO, Smith AN, Brydon WG (1987) Diagnosis of acute pancreatitis: A proposed sequence of biochemical investigation. Scand J Gastroenterol 22: 719-724. [Crossref]

12. Vissers RJ, Abu-Laban, Mc Hugh DF (1999) Amylase and lipase in the emergency department evaluation of acute pancreatitis. J Emerg Med 17: 1027-1037. [Crossref]

13. Yadav D, Agrawal N, Pitchumoni CS (2002) A critical evaluation of laboratory tests in acute pancreatitis. Am J Gastroenterol 97: 1310-1316. [Crossref]

14. Sackett D, Haynes R, Guyatt (1991) Clinical epidemiology-A basic science for clinical medicine. Boston: Little, Brown and Company.

15. Lott JA, Patel ST, Sawhney AK, Kazmierczak SC, Love JE, et al. (1986) Assays of serum lipase: analytical and clinical considerations. Clin Chem 32: 1290-1302. [Crossref]

16. Tetrault GA (1991) Lipase activity in serum measured with Ektachem is often increased in nonpancreatic disorders. Clin Chem 37: 447-451. [Crossref]

17. Clave P, Guillaumes S, Blanco I, Nabau N, Merce J, et al. (1995) Amylase, lipase, pancreatic isoamylase and phospholipase A in diagnosis of acute pancreatitis. Clin Chem 41: 1129-1134. [Crossref]

18. Lott JA, Lu CJ (1991) Lipase isoforms and amylase isoenzymes: assays and application in the diagnosis of acute pancreatitis. Clin Chem 37: 361-368. [Crossref]

19. Werner M, Steinberg W, Pauley C (1989) Strategic use of individual and combined enzyme indicators for acute pancreatitis. Clin Chem 35: 967-971. [Crossref]

20. Kazmierczak S, Catrou P, VanLente F (1993) Diagnostic accuracy of pancreatic enzymes evaluated by use of multivariate data analysis. Clin Chem 39: 1960-1965. [Crossref]

21. Garrison R (1986) Amylase. Emerg Med Clin North Am 4: 315-327. [Crossref]

22. Sacher RA, McPherson RA, Campos JM (1991) Widmann's clinical interpretation of laboratory tests. Philadelphia: F. A. Davis Company.

23. Holdsworth PJ, Mayer AD, Wilson DH, Flowers MW, McMahon MJ (1984) A simple screening test for acute pancreatitis. Br J Surg 71: 958-959. [Crossref]

24. Gunn IR, Faye S, Clayton MG (1986) Prospective evaluation of urinary amylase test strip. Lancet 1: 1161. [Crossref]

25. Andriushchenko VP, Lysiuk IuS, Barvins'ka AS (1998) Diagnostic and prognostic significance of urinary amylase in acute biliary pancreatitis. Klin Khir 3: 17-18. [Crossref]

26. Keim V, Teich N, Fiedler F, Hartig W, Thiele G, et al. (1998) A comparison of lipase and amylase in the diagnosis of acute pancreatitis in patients with abdominal pain. Pancreas 16: 45-49. [Crossref]

27. Clavien PA, Robert J, Meyer P, Borst F, Hauser H et al. (1989) Acute pancreatitis and normoamylasemia . Not an uncommon combination. Ann Surg 210: 614-620. [Crossref]

28. Winslet M, Hall C, London NJ (1992) Relation of diagnostic serum amylase level to aetiology and severity of acute pancreatitis. Gut 33: 982-986. [Crossref]

29. Spechler SJ, Dalton JW, Robbins AH, Gerzof SG, Stern JS, et al. (1983) Prevalence of normal serum amylase levels in patients with acute alcoholic pancreatitis. Dig Dis Sci 28: 865-869. [Crossref]

30. Warshaw AL, Bellini CA, Lesser PB (1975) Inhibition of serum and urine amylase activity in pancreatitis with hyperlipemia. Ann Surg 182: 72. [Crossref]

31. Ventrucci M, Pezzilli A, Naldoni P, Plate L, Baldoni F, et al. (1987) Serum pancreatic enzyme behavior during the course of acute pancreatitis. Pancreas 2: 506-509. [Crossref]

32. Kiriyama S, Gabata T, Takada T, Hirata K, Yoshida M, et al. (2010) New diagnostic criteria of acute pancreatitis. J Hepatobiliary Pancreat Sci 17: 24-36. [Crossref]

33. Berk JE, Kizu H, Wilding PE, Searcy RL (1967) Macroamylasemia: a newly diagnosed cause for elevated serum amylase activity. N Engl J Med 277: 941-946.

34. Helfat A, Berk JE, Frindhandler L (1974) The prevalence of macroamylasemia. Further study. Am J Gastroenterol 62: 54-58. [Crossref]

35. Bode C, Riederer J, Brauner B, Bode JC ( 1990) Macrolipasemia: a rare cause of persistently elevated serum lipase. Am J Gastroenterol 85: 412-416. [Crossref]

36. Tietz NW (1997) Support of the diagnosis of pancreatitis by enzyme test- old problems, new techniques. Clinica Chimica Acta 257: 85-98. [Crossref]

37. Pezzilli R, Billi P, Miglioli M, Gullo L ( 1993) Serum amylase and lipase concentrations and lipase/amylase ratio in assessment of etiology and severity of acute pancreatitis. Dig Dis Sci 38: 1265-1269. [Crossref]

38. Ranson JH (1982) Etiologic and prognostic factors in human acute pancreatitis: a review. Am J Gastroenterol 77: 633-638. [Crossref]

39. Blamey SL, Imrie CW, O'Neill J, Glimour WH, Carter DC ( 1984) Prognostic factors in acute pancreatitis. Gut 25: 1340-1346. [Crossref]

40. Coffey MJ, Nightingale S, Ooi CY ( 2013) Serum Lipase as an Early Predictor of Severity in Pediatric Acute Pancreatitis. JPGN 56: 602-608. [Crossref]

41. Tenner SM, Steinberg W (1992) The admission serum lipase: amylase ratio 
differentiates alcoholic from nonalcoholic acute pancreatitis. Am J Gastroenterol 87: 1755-1758. [Crossref]

42. Lankisch PG, Petersen M (1994) Lipase/amylase ratio: not helpful in the early etiological differentiation of acute pancreatitis. Z Gastroenterol 32: 8-11. [Crossref]

43. Banks PA (1997) Practice guidelines in acute pancreatitis. Am J Gastroenterol 92: 377-386.

44. Banks PA, Freeman ML (2006) Practice Parameters Committee of the American College of Gastroenterology. Practice guidelines in acute pancreatitis. Am J Gastroenterol 101: 2379-2400. [Crossref]

45. Hiatt JR, Calabria RP, Passaro E, Wilson SE (1987) The amylase profile: A discriminant in biliary and pancreatic disease. Am J Surg 154: 490-492. [Crossref]

46. Corsetti JP, Cox C, Schulz TJ, Arvan DA (1993) Combined serum amylase and lipase determinations for diagnosis of suspected acute pancreatitis. Clin Chem 39: 2495-2499. [Crossref]

47. Saez J, Martınez J, Trigo C, Sanchez-Paya J, Company L, et al. (2005) Clinical value of rapid urine trypsinogen-2 test strip, urinary trypsinogen activation peptide, and serum and urinary activation peptide of carboxypeptidase B in acute pancreatitis. World $J$ Gastroenterol 11: 7261-7265. [Crossref]

48. Lin XZ, Chen TW, Wang SS (1988) Pancreatic enzymes in uremic patients with or without dialysis. Clin Biochem 21: 189-192. [Crossref]

49. Gumaste VV, Roditis N, Mehta D, Dave PB (1993) Serum lipase levels in nonpancreatic abdominal pain versus acute pancreatitis. Am J Gastroenterol 88: 2051-2055. [Crossref]

50. Warshaw AL, Fuller AF Jr (1975) Specificity of increased renal clearance of amylase in diagnosis of acute pancreatitis. $N$ Engl J Med 292: 325-328.

51. Pollack AV (1959) Acute pancreatitis: analysis of 100 patients. Br Med J 1: 6-14 [Crossref]

52. Lankisch PG, Burchard-Recker IS, Lehrich D (1999) Underestimation of acute pancreatitis: Patients with only a small increase in amylase/lipase levels can also have or develop severe acute pancreatitis. Gut 44: 542-544. [Crossref]

53. Lang E, Afilalo M, Dankoff J, Colacone A, Tselios C, et al. (1995) The prognostic significance of moderate hyperamylasemia in the evaluation of the emergency department patient. J Emerg Med 13: 107-112. [Crossref]

Copyright: $₫ 2015$ Jasdanwala S. This is an open-access article distributed under the terms of the Creative Commons Attribution License, which permits unrestricted use, distribution, and reproduction in any medium, provided the original author and source are credited. 